\title{
A quebra do Político Profissional: a Necessidade da Participação Popular
}

\author{
Breach of Political Training: the Need for Popular Participaction
}

Gabriela Soares Balestero $^{1}$

\begin{abstract}
Resumo
O presente artigo faz uma análise do político caricato, que vive da política e não vive para a política, somente desejando alcançar o poder e fazer da política um meio de vida. Quanto mais se fala em ética e política, mais se percebe que seus caminhos são paralelos e raramente se cruzam. Também serão discutidas no presente estudo a análise da vida pregressa dos candidatos bem como a Lei Complementar n. 135 de 04 de junho de 2010. O ideal é a retomada da democracia participativa direta, mais precisamente o recall, de forma a haver a divisão de responsabilidade entre governante e administrado na tomada de decisões e assim o controle da população sobre os seus representantes.
\end{abstract}

Palavras Chave: Política. Meio de vida. Ética. Democracia participativa direta. Recall.

\begin{abstract}
In the present article will analyze the role of the politician who wishes to gain power and make the policy a living. It is the political caricature that lives by political and not live for politics. The more you talk about ethics and politics, the more they realize that their paths are parallel and rarely meet. Also discussed in this paper the analysis of the previous life of the candidates and the Complementary Law n. 135, June 4, 2010. Ideally, the resumption of direct participatory democracy, namely the recall, to be the division of responsibility between ruler and administered in making decisions and so the population control over their representatives.
\end{abstract}

Keywords: Policy. Livelihoo. Ethics. Participatory direct democracy. Recall.

\section{Introdução}

O político que almeja alcançar o poder em boa parte das vezes deseja fazer da política o seu meio de vida. Para ele seria como se fosse um emprego que, usando as regras do jogo leva o candidato a subir.

As Comissões de Ética das Casas Legislativas ou as Corregedorias dos outros poderes mostram claramente que poucos são aqueles que são punidos apesar dos

\footnotetext{
1 Mestranda em Direito Constitucional pela Faculdade de Direito do Sul de Minas, especialista em Direito Constitucional e em Direito Processual Civil pela Faculdade de Direito do Sul de Minas, bacharel em Direito pela Universidade Presbiteriana Mackenzie. Advogada.
} 
escândalos. As Corregedorias do Executivo apresentam em números escândalos, denúncias de corrupção, contudo, os condenados pelas corregedorias ainda são poucos.

O mesmo ocorre com o Poder Judiciário em que as corregedorias apresentam um pequeno número de condenações apesar das inúmeras denúncias a esse respeito².

Para o político de carreira, sua carreira de longe é mais importante do que a sua obrigação de servir. Portanto, ao estudarmos o político de carreira não há como deixarmos de perceber o carreirismo, ou seja, a busca da profissão de agente público pelo governante, servindo a si mesmo mais do que à sociedade.

Weber traça um amplo panorama crítico da atividade política no mundo moderno, na qual se inclui uma exposição sobre o nascimento e evolução dos partidos. Como em todos os outros fenômenos que analisa, também neste caso, o autor vai buscar na comparação histórica, os ancestrais dos partidos modernos. Os exemplos que Weber dá são os agrupamentos políticos medievais, como os guelfos e os gibelinos das cidades italianas. Esses agrupamentos eram baseados fundamentalmente em séquitos pessoais, que competiam por poder político, e terras, fazendo da violência o instrumento normal da conquista. Desenvolvendo já sua crítica ao processo revolucionário que se dava na Rússia, Weber também vai buscar como exemplo de organização política pré-partidária a organização paramilitar rígida dos soviets russo.

Nesse estudo será analisado os governantes que vivem da política e aquelas que vivem para a política, a necessidade de averiguação da vida pregressa do candidato, a Lei do Ficha Limpa e o recall, sendo esse o objetivo do presente artigo.

\section{A análise da Vida Pregressa dos Candidatos feita pelo Judiciário}

Será analisada a questão da "lista negra dos candidatos", ressaltando o julgamento improcedente pelo Supremo Tribunal Federal da Argüição de Descumprimento de Preceito Fundamental (ADPF 144) interposta pela Associação dos Magistrados Brasileiros - AMB,

\footnotetext{
2 Se os historiadores anteriores a mim tivessem sido omissos no elogio da História, talvez me fosse necessário recomendar a todos os leitores a preferência para seu estudo e uma acolhida favorável aos tratados como este, pois nenhum outro corretivo é mais eficaz para os homens que o conhecimento do passado. Entretanto, não somente alguns, mas todos os historiadores, e não de maneira dúbia mas fazendo dessa idéia o princípio e o fim de seu labor, procuram convencer-nos de que a educação e o exercício mais sadios para uma vida política ativa estão no estudo da História, e que o mais seguro na realidade o único método de aprender a suportar altivamente as vicissitudes da sorte é recordar as calamidades alheias." (POLÍBIOS, 1982, p. 41)
} 
contrariando o entendimento de que os juízes eleitorais possam rejeitar candidaturas de réus em ações penais e processos de improbidade administrativa.

A lei eleitoral (lei 9.504 de 30 de setembro de 1997) estabelece que o pedido de registro dos candidatos deva ser instruído com vários documentos, inclusive com certidões criminais fornecidas pelos órgãos de distribuição da Justiça Federal e Estadual (art. 11, § 1으, VII).

Além disso, na avaliação da vida pregressa do pré - candidato, "caso entenda necessário, o Juiz abrirá prazo de 72 horas para diligências." (§ 3ํ, do mesmo artigo II).

No aludido artigo II, "os tribunais e Conselhos de Contas deverão tornar disponíveis a Justiça Eleitoral relação dos que tiverem suas contas relativas ao exercício de cargos ou funções públicas rejeitadas por irregularidade insanável e por decisão irrecorrível do órgão competente. “(§ 5ㅇ).

Verifica-se a tentativa de proteger a moralidade administrativa para o exercício do mandado ao analisar a vida pregressa do candidato a cargos eletivos.

Recentemente, o Supremo Tribunal Federal julgou improcedente a Argüição de Descumprimento de Preceito Fundamental (ADPF 144) interposta pela Associação dos Magistrados Brasileiros - AMB, contrariando o entendimento de que os juízes eleitorais possam rejeitar candidaturas de réus em ações penais e processos de improbidade administrativa.

Segundo o entendimento do Ministro Gilmar Mendes, Presidente do Supremo Tribunal Federal, é compreensível a repercussão do tema na opinião pública. "A população passa a acreditar que a lista (com os nomes dos candidatos que respondem a processos) será a solução de todas as mazelas, mas a missão dessa Corte constitucional é aplicar a Constituição ainda que essa decisão seja contrária ao pensamento da maioria".

Contudo, a decisão do Supremo Tribunal Federal se pautou no entendimento do art. 5o, inciso LVII, da Constituição Federal ao advertir que "ninguém será considerado culpado até o trânsito em julgado da sentença penal condenatória." O caso da ADPF trata da lista de candidatos réus em processos penais e de probidade administrativa.

O ministro Lewandowski afirmou que o Supremo Tribunal Federal compartilha do anseio popular que atualmente encontra enfática repercussão nos meios de comunicação, no sentido de que sejam impedidos de concorrer a cargos eletivos os candidatos que não 
tenham a qualificação legal ou moral para tanto, mas deve fazer isso dentro das balizas constitucionais e legais em vigor.

Nesse sentido, é imperiosa a concordância com posicionamento do Ministro Eros Grau, pois se não for respeitado o trânsito em julgado, será instalado no país, um estado de insegurança jurídica e de delação que remete aos regimes autoritários.

Ademais, é necessária uma reforma legislativa e constitucional a esse respeito, e não o simples fatos de os juízes, baseados na discricionariedade, considerarem que candidatos que respondam a processo sejam inelegíveis, ou que apenas a sentença de primeira instância possa levar à inelegibilidade, pois isso geraria uma enorme insegurança jurídica, além de violar o princípio constitucional da presunção de inocência.

A tese vencedora foi inaugurada pelo ministro Celso de Mello. Para ele, impedir a candidatura de políticos que respondem a processo viola os princípios constitucionais da presunção de inocência e do devido processo legal. Seguiram esse entendimento os ministros Carlos Alberto Menezes Direito, Carmem Lúcia Antunes Rocha, Ricardo Lewandowski, Eros Grau, Cezar Peluso, Ellen Gracie, Marco Aurélio e Gilmar Mendes.

Já Moreira Alves apresentou um entendimento muito peculiar no sentido de que a inelegibilidade seria aplicada ao candidato às eleições municipais deste ano que já estivesse sido condenado em segunda instância.

O Poder Judiciário e a Administração Pública não podem atuar como legislador, criando regras de inelegibilidade não previstas na Constituição e na Lei Complementar sobre a matéria.

A lei complementar deve estabelecer outros casos de inelegibilidade a fim de proteger a probidade administrativa, a moralidade para o exercício do mandato, considerada a vida pregressa do candidato, e a normalidade e legitimidade das eleições contra a influência do poder econômico ou o abuso do exercício da função, cargo ou emprego na administração direta ou indireta, e não deixar à cargo do entendimento dos juízes eleitorais de acordo com o caso em concreto.

Logicamente, o Brasil provavelmente seria outro se, pessoas com a sua vida pregressa comprometida com o crime, com a imoralidade e com a falta de ética, não se incluíssem entre os candidatos que devam representara a sociedade civil. 
Depois de um julgamento que durou aproximadamente oito horas, o Supremo Tribunal Federal negou por 9 votos a 2, o pedido da AMB (ADPF n. 144) para que a justiça eleitoral pudesse negar pedido de registro de candidatos que respondem a processos.

Segundo o Ministro Gilmar Mendes a decisão o Supremo Tribunal Federal tem efeito vinculante, devendo ser seguida pela justiça eleitoral e que candidatos que tenham o seu pedido de registro de candidatura recusado poderão recorrer ao Supremo, ingressando com uma Reclamação.

O Ministro Cezar Peluso em seu voto alegou que a pretensão da AMB implica, inicialmente, a idéia de revogação das normas e, em segundo lugar, a introdução da liberdade judicial para criar casos de inelegibilidade, isto é, valeria não a regra objetiva, mas a vontade do juiz.

Além disso, o Ministro Eros Grau em seu voto argumentou o respeito ao princípio constitucional da presunção de inocência até que uma ação judicial transite em julgado (no caso trata-se da candidatura de réus em processos penais e de probidade administrativa), pois se isso não fosse respeitado, se instauraria um estado de insegurança jurídica no país.

Nesse passo, conclui-se que no Direito Moderno é necessário o respeito ao devido processo legal, ao contraditório, a ampla defesa, bem como o princípio da presunção da inocência.

Portanto, essa liberdade judicial para criar casos de inelegibilidade equivaleria mais à vontade do juiz de acordo com o caso concreto, gerando inconstitucionalidade e insegurança jurídica. Desta forma, era imprescindível a reforma legislativa e constitucional a esse respeito, no sentido de preservação da moralidade administrativa, porém não da maneira com que a vida pregressa dos candidatos vinha sendo tratada pelo Poder Judiciário.

\section{A Lei Complementar n. 132 de 04 de junho de 2010: "Ficha Limpa"}

A Lei Complementar n. 135/2010 apelidada de a lei da "ficha limpa", entrou em vigor em junho de 2010, oriunda de um processo legislativo célere devido às eleições deste ano.

O projeto da ficha limpa se originou de uma campanha feita pela sociedade civil brasileira com o fim de melhorar o perfil dos candidatos a cargos eletivos no país. O projeto 
de lei da ficha limpa foi oriundo da iniciativa popular a respeito da vida pregressa dos candidatos com o fim de criar critérios de inelegibilidades mais rígidos.

A iniciativa popular é um instrumento de participação popular direta previsto constitucionalmente, na qual, entre outras condições, mediante a coleta de assinaturas de $1 \%$ de todos os eleitores brasileiros, pode ser apresentado um projeto de lei ao Congresso Nacional.

No projeto Ficha Limpa foram coletadas mais de 1,3 milhões de assinaturas, o que corresponde a $1 \%$ dos eleitores brasileiros, sendo entregues ao Congresso Nacional no dia 29 de setembro de 2009.

A Lei da Ficha Limpa criou novos casos de inelegibilidade ${ }^{3}$ como aqueles que foram condenados em decisão transitada em julgado ou em decisão colegiada, ou seja, dos tribunais, por abuso do poder econômico ou político, para a eleição na qual concorrem ou tenham sido diplomados, bem como para as que se realizarem nos 8 anos seguintes; mesmo que a decisão ainda seja recorrível; e os que forem condenados, em decisão transitada em julgado ou proferida por órgão judicial colegiado, desde a condenação até o transcurso do prazo de 8 (oito) anos após o cumprimento da pena, por crimes arrolados no artigo $2^{\circ}$ da Lei Complementar de n. 134 de 04 de julho de 2010.

Após a Lei da Ficha Limpa ${ }^{4}$ o Tribunal Superior Eleitoral negou autorização para

\footnotetext{
3 Menos de um mês depois o STF concedeu liminar para que dois parlamentares fossem excluídos do raio de sua incidência, pelo menos para a próxima eleição. O primeiro foi o Senador Heráclito Fortes, do partido Democratas (PI), depois foi a vez da deputada estadual de Goiás, Isaura Lemos do PDT. No caso do Senador Heráclito Fortes, ele já havia sido condenado por órgão colegiado do Tribunal de Justiça do Piauí por "condutas lesivas ao patrimônio público". O Min. Gilmar Mendes, que concedeu a liminar, justificou a decisão pela urgência, já que o STF não julgaria o mérito da ação antes do prazo final para registro da candidatura. Na decisão do processo da deputada de Goiás, foi suspensa condenação da 1ạ Vara da Fazenda Pública - que já havia sido confirmada no Tribunal de Justiça do Estado -, dando-se liminar para que o STF julgue Recurso Extraordinário por ela interposto (BAHIA, 2010, p. 6).

${ }^{4}$ Vale lembrar que esta lei foi o quarto projeto de lei de iniciativa popular a ser aprovado pelo Congresso Nacional desde 1988. Noutra oportunidade lamentamos a letargia do Congresso em cumprir sua função: legislar.Entretanto, faltam iniciativas como essa em que os cidadãos tomam a frente e mobilizam o legislador. Em um Estado Democrático de Direito a cidadania deve ser considerada, mais do que nunca, como o direito de participação na formação da vontade política, nos seus diferentes níveis. Não há pré-requisitos para a cidadania, de forma que primeiro se tenha que ter um povo educado e saudável para, então, ter cidadãos; aliás, é justamente aquele que mais necessita do cumprimento das promessas não realizadas da Constituição que deve exigir seu cumprimento. Sob esse ponto de vista, muito louvável a mobilização feita em torno da lei. Lembremos, contudo, que, por mais interessante que a lei possa parecer, ela padece de um vício grave: ao tornar inelegíveis aqueles cujos processos ainda estão pendentes de decisão final, viola o princípio constitucional da presunção de inocência, o que não pode ser tolerado e levará, possivelmente, à declaração judicial de sua inconstitucionalidade, como já acenou o Min. Toffoli no julgamento do caso da deputada goiana citada (BAHIA, 2010, p. 6).
} 
registro de candidaturas que tinham contas a prestar. Em seguida, o Ministério Público movimentou-se para impugnar cerca de 400 candidaturas em todo o País.

\section{O Político Profissional: Weber}

No Brasil, o aperfeiçoamento da democracia inevitavelmente percorre uma crise, sobretudo de representação e as divergências no campo democrático se iniciam no imperativo de que o exercício do poder deve ser legitimado pelo povo. A crise da democracia representativa pode ser observada na postura do Poder Judiciário em inibir candidaturas de pessoas que possuam processos judiciais contra si, bem como da Lei do Ficha Limpa que criou novos casos de inelegibilidades.

O político para alcançar o poder muitas vezes pretende fazer da política o seu meio de vida. A ética ${ }^{5}$ e a política possuem caminhos paralelos que raramente se cruzam.

Nesse passo, a democracia seria um meio utilizado para eleger membros da elite para dirigir o Estado, ou seja, os indivíduos alcançam o poder através de uma luta concorrencial pelo voto popular.

\footnotetext{
${ }^{5}$ Entretanto, o segundo argumento é sujeito a objeções que levam Nagel a reconsiderá-lo em favor de uma versão reformulada do primeiro argumento da reciprocidade (cf. Nagel, 1991, p. 163). Ele vê o critério para exercer o controle político dos "fins mais centrais da autorrealização" (ibidem, p, 164), aos quais pertence a liberdade de escolher sua própria vida boa. $\mathrm{O}$ argumento kantiano da reciprocidade é fortalecido a ponto de se considerar que somente razões que outros poderiam aceitar conferem o direito de agir de acordo com essas razões - na medida em que é atingido um determinado domínio central das questões morais (do qual se segue novamente o problema, ainda a ser discutido, de definir esse domínio.) Ao reformular seu argumento epistemológico, Nagel reage a objeções, como aquelas levantadas por Raz (1990, p. 36-46), que questionam a possibilidade de que as pessoas possam manter suas convicções como sendo simultaneamente verdadeiras e, num certo sentido - a saber, depois de assumir o ponto de vista "imparcial"-, como não verdadeiras, respectivamente, como meramente uma crença ou conviç̧ão. A "separação epistemológica entre privado e público", proposta por Nagel, não faz justiça ao caráter do que significa considerar algo como verdadeiro. O que se considera correto "privativamente" também se defende "publicamente" (FORST, 2010, p. 54).
} 
Para Max Weber haveriam duas maneiras ${ }^{6}$ de fazer política: "Ou se vive para a política, ou se vive da política. Quem vive para a política, a transforma, no sentido mais profundo do termo, em "fim de sua vida", seja porque o exercício dessa atividade lhe permite achar o equilíbrio interno e exprimir valor pessoal, colocando-se a serviço de uma "causa"que dá significação a sua vida.

O homem político profissional, que vive da política ${ }^{7}$, pode ser um puro beneficiário, ou um funcionário remunerado. Eis o preço que importa pagar pela colocação de verdadeiros chefes à testa de um partido; só uma escolha cabe: ou uma democracia admite como dirigente um verdadeiro chefe e, por conseqüência, aceita a existência da máquina, ou rega os chefes e cai sob o domínio dos políticos profissionais, sem vocação, privados das qualidades carismáticas que produzem os chefes.

De modo geral, o desenvolvimento do Estado moderno tem por ponto de partida o desejo de o príncipe expropriar os poderes "privados" independentes que, a par do seu, detêm força administrativa, isto é, todos os proprietários de meios de gestão, de recursos financeiros, de instrumentos militares e de quaisquer espécies de bens suscetíveis de utilização para fins de caráter político. Esse processo se desenvolve em paralelo perfeito com o desenvolvimento da empresa capitalista que domina, a pouco e pouco, os produtores independentes. E nota-se enfim que, no Estado moderno, o poder que dispõe da totalidade dos meios políticos de gestão tende a reunir-se sob mão única (WEBER, 1967, p. 61)

6 Em A Política Como Vocação, tal interesse se volta para as condições necessárias ao funcionamento do Estado moderno, para a burocracia como organização social baseada numa orientação zwecrational de ações e nas conseqüências da burocratização do Estado moderno para a sociedade em que se encontra inserido. Para Weber, diferentes tipos de sociedades apresentam diferentes formas de liderança política. Entretanto, a manutenção dessas lideranças depende de organizações administrativas que realizam a "expropriação" política. São tais organizações que irão, afinal de contas, determinar a "racionalidade" do sistema político; são elas que irão exercer, com maior ou menor sucesso, o monopólio do poder de uma sociedade. A "racionalidade" de semelhantes organizações depende, em primeiro lugar, de uma distinção entre "viver para a política" e "viver da política". Ainda que Weber não o afirme categoricamente, essa distinção ajuda a compreender as motivações da ação política e, por sua vez, gera o problema da corrupção, na organização política. Em segundo lugar, a racionalidade do sistema político aumenta na medida em que ocorrem uma diferenciação de status papéis e uma especialização funcional dentro das organizações administrativas. A brilhante e erudita análise de Weber sugere que a diferenciação ocorre quando há uma especialização entre a administração, que deve ser exercida sine ira et studio, e a liderança política, cuja ação é, por natureza, fundamentada na ira et studium. Essa especialização, por sua vez tende a mudar os critérios de alocação de status - papéis na organização política. Os critérios deixam de ser plutocráticos e passam a basear-se no desempenho e no conhecimento especializado. Não há portanto, nessa nova organização, lugar para o dilettante, pois o seu "sucesso" depende, cada vez mais, da ação especializada (BERLINCK, 1967, p. 12.)

7 Maquiavel, em $O$ Príncipe, embora idealizando o comportamento do governante determinado pela manutenção do poder, com ética ou sem ela, de rigor, não se dirige apenas aos príncipes da época, mas a todos aqueles que, em todos os tempos, lutam por governar. Em outras palavras, na grande maioria dos casos, ao estudarmos o perfil do político de carreira, não há como deixarmos de perceber o carreirismo, que torna a busca da profissão de agente público o melhor caminho para uma forma de bem viver, servindo a si mesmo mais do que à sociedade (MARTINS, 2009, p. 108.). 


\title{
O Estado Moderno passa a ser um agrupamento de dominação em que os
}

dirigentes mais poderosos dominam os pequenos estados, ou seja, a violência legitima o domínio nas mãos dos dirigentes que possuem meios materiais para tal mister.

\begin{abstract}
Sem embargo, ao longo desse processo de expropriação que se desenvolveu, com êxito maior ou menor, em todos os países do globo, nota-se o aparecimento de uma nova espécie de "políticos profissionais". Trata-se, no caso, de uma categoria nova, que permite definir o segundo sentido dessa expressão. Vemo-los, de início, colocarem-se a serviço dos príncipes. Não tinham a ambição dos chefes carismáticos e não buscavam transformar-se em senhores, mas empenhavam-se na luta política para se colocarem à disposição de um príncipe, na gestão de cujos interesses políticos encontravam ganha - pão e conteúdo moral para suas vidas. Uma vez mais, é só no Ocidente que encontramos essa categoria nova de políticos profissionais a serviço de poderes outros que não o dos príncipes. Não obstante, foram eles, em tempos passados, o instrumento mais importante do poder dos príncipes e da expropriação política que, em benefício destes, se processava (WEBER, 1967, p. 62-63).
\end{abstract}

Na realidade, os discursos políticos não devem ser neutros, entretanto é importante que sejam marcados com argumentos éticos ${ }^{8}$, para inclusive justificar as ações do político perante o público.

\begin{abstract}
No momento que um homem, ou uma classe de homens, se encontra com o poder nas mãos, o interesse individual dele, ou o interesse distinto da classe, adquire totalmente um novo grau de importância aos seus olhos. Quando ele se vê adorado por outros, torna-se adorador de si mesmo e considera-se no direito de ter o próprio valor contado cem vezes mais do que o valor de outras pessoas; enquanto a facilidade que ele adquire de fazer o que quer, sem considerar as conseqüências, enfraquece insensivelmente os hábitos que fazem os homens ficar na expectativa que tais conseqüências possam até mesmo afetá-los.

Portanto, um dos maiores perigos da democracia, assim como de todas as outras formas de governo, está no interesse ameaçador dos que ocupam o poder; é o perigo da legislação em favor de uma classe; do governo destinado (realmente colocando-o em prática ou não) ao benefício imediato da classe dominante, em detrimento permanente de todos. Uma das questões mais importantes que deve ser levada em consideração para determinar a melhor constituição de um governo representativo é como proporcionar medidas eficazes contra este mal (MILL, 2006, p. 106).
\end{abstract}

\footnotetext{
8 “A questão central é que a pessoa de direito é apenas a proteção abstrata de identidades concretas na forma do reconhecimento universal e igual - uma proteção abstrata que não pressupõe que os valores éticos não sejam levados a sério e nem que os princípios morais do reconhecimento igual sejam meras fórmulas de compromisso. Assim, Dworkin destaca: 'O liberalismo não pode ser baseado no ceticismo. Sua moralidade constitutiva afirma que os seres humanos têm de ser tratados como iguais por seus governos, não porque não existe o certo e o errado na moralidade política, mas porque isso é o que é correto." (FORST, 2010, p. 69).
} 
A Lei da Ficha Limpa é um exemplo de participação na formação da vontade política, na mobilização do Poder Legislativo, contudo, ela possui um vício grave de constitucionalidade, pois ao tornar inelegíveis aqueles cujos processos ainda estão pendentes de decisão final, há a violação do princípio constitucional da presunção de inocência, e provavelmente, se argüido perante o Supremo Tribunal Federal levará à declaração judicial de sua inconstitucionalidade.

\section{A Necessidade de Criação de um Novo Sistema de Participação Popular: o Recall}

O papel infeliz desempenhado pelos "políticos profissionais", como já analisado anteriormente, gera uma crise no sistema democrático diante da "quebra" de institutos inicialmente participativos, da transformação do processo eleitoral em uma troca de interesses, de favores pessoais, em vez de ser uma esfera pública de discussões, da descrença dos cidadãos em nossos representantes, bem como a falta de interesse em compreender o que seria realmente a participação popular em um regime democrático.

Apesar da Lei do Ficha Limpa ser oriunda da iniciativa popular, o que é louvável, na verdade é necessária a criação de novos sistemas de participação popular consubstanciados no controle sobre os mandados eletivos que possibilitem a dissolução pelo eleitorado de agentes políticos que não estejam lhes agradando.

\footnotetext{
Quais são, agora, as alegrias íntimas que a carreira política pode proporcionar a quem a ela se entrega e que prévias condições seria preciso supor?

Bem, ela concede, antes de tudo, o sentimento de poder. A consciência de influir sobre outros seres humanos, o sentimento de participar do poder e, sobretudo, a consciência de figurar entre os que detém nas mãos um elemento importante da história que se constrói podem elevar o político profissional, mesmo o que só ocupa modesta posição, acima da banalidade da vida cotidiana. Coloca-se, porém, a esse propósito, a seguinte pergunta: quais são as qualidades que the permitem esperar situar-se à altura do poder que exerce (por pequeno que seja) e, consequentemente, à altura da responsabilidade que esse poder lhe impõe? Essa indagação nos conduz à esfera dos problemas éticos (WEBER, 1967, p. 105).
}

O recall ou referendo revocatório é um instituto novo de participação popular que vem sendo adotado com sucesso em países no combate ao excesso de poder dos governantes. 
Paulo Bonavides (2000, p. 292) conceitua o instituto da seguinte forma: "É a forma de revogação individual. Capacita o eleitorado a destituir funcionários, cujo comportamento, por qualquer motivo, não lhe esteja agradando".

Segundo, Alberto Antonio Zvirblis $(2006$, p. 70 ) assevera que o recall "se constitui na revogação do mandato. É a retirada do poder de alguém que tenha sido eleito para uma função pública".

O recall ${ }^{9}$ é o referendo revocatório de mandatos eletivos, sendo um instrumento de participação onde determinado número de eleitores, não satisfeitos com a conduta de seu representante no poder, determina sua remoção do cargo. Ou seja, o povo elege e pode destituir, substituindo o velho impeachment.

Porém infelizmente a Proposta de Emenda Constitucional n. 73 de 2005 ainda não foi votado pelo legislativo federal, sendo muito difícil de conseguir aprovação. Mas a discussão já entrou na agenda política.

\begin{abstract}
O sistema representativo deve ser constituído de forma tal a manter esta situação; não deve permitir que qualquer dos vários interesses seccionais torne-se tão poderoso que seja capaz de prevalecer contra a verdade e a justiça e contra outros interesses parciais combinados. Sempre deverá existir um equilíbrio tal preservado entre os interesses pessoais que faça com que qualquer um deles dependa, para seu êxito, da possibilidade de obter o apoio de pelo menos grande parte daqueles que agem baseados em motivos mais elevados e opiniões mais abrangentes de maior alcance (MILL, 2006, p. 109-110).
\end{abstract}

O instituto do recall tem origem norte americana, sendo introduzido em 1.903 na Carta de Los Angeles por Theodore Roosevelt.

Segundo Sgarbi (1999, p. 99) que:

[...] é possível, encontrar, em outros sistemas, e com inúmeras oscilações terminológicas, sua previsão. Assim em algumas províncias da Argentina que o chamam de destituição, e com as antigas Constituições das Repúblicas Socialistas Soviéticas, que o nominavam de revogação.

Um dos países latino - americanos que adotou o instituto do recall é a Venezuela no seu art. 72 da Constituição da República Bolivariana da Venezuela, denominado de referendo revocatório de todos os cargos eletivos.

\footnotetext{
9 "Se o sistema distrital pode, de um lado, fortalecer a relação entre representantes e representados, baratear as eleições para o candidato (nunca para o partido) e facilitar o funcionamento do recall, os problemas dele decorrentes podem ser muito graves." (MAGALHÃES, 2002, p. 40.)
} 
Consoante Bonavides (2000, p. 292), “Doze Estados-membros da União americana aplicam o recall, que tem mais voga na esfera municipal do que na estadual. Cerca de mil municípios americanos o adotam. A instituição inexiste no plano federal".

Atualmente, há um projeto de Emenda Constitucional (SF PEC 00073/2005 de 09/12/2005) de autoria do Senador Eduardo Suplicy que ainda está sem julgamento no Congresso Nacional.

O instituto do recall apesar de sempre fazer parte de discussões políticas ainda não foi implantado, ou seja, esse projeto ainda não foi convertido em lei pelo Congresso Nacional.

O povo, legítimo detentor do poder soberano, possui total liberdade de eleger os seus representantes, contudo, não possuem meios eficazes para destituí-los do poder, ainda que estejam praticando atos violadores do bem comum.

Portanto, é necessário dar ao povo meios para que possa corrigir as mazelas do sistema representativo e destituir os seus governantes quando violarem os objetivos perseguidos pelo Estado Democrático de Direito.

A introdução do instituto do recall ou da revogação popular de mandatos eletivos dará maior legitimidade à soberania do povo e proporcionará o fortalecimento e o amadurecimento político das intuições democráticas.

\begin{abstract}
Efetivamente falar em vontade do povo parece na maioria dos casos uma ficção. Nas sociedades cada vez mais complexas, não há uma vontade popular, mas várias, que representam interesses de setores, de grupos, de forças diversas presentes na sociedade contemporânea. Não há, nunca houve e é impossível que haja uma única vontade permanente do povo. Diante de uma sociedade cada vez mais complexa, podemos dizer que a democracia representativa irá cumprir um papel importante no processo democrático, o que é o de, principalmente, dar transparência, visibilidade, aos grandes debates, aos grandes temas nacionais e globais, permitindo que a sociedade organizada atue de forma democrática no diálogo nacional nos meios de comunicação social, nas ruas, nos sindicatos, enfim, podemos dizer que o elemento mais democrático desse processo é o povo nas ruas. A pressão e o diálogo na sociedade civil é elemento determinantes para a existência de uma democracia, e não o voto (MAGALHÃES, 2002, p. 163).
\end{abstract}

O projeto de EC no. 73/2005, de autoria do Senador Eduardo Suplicy, altera dispositivos dos arts. 14 e 49 da Constituição Federal e acresce o artigo 14-A, prevendo a possibilidade de revogação do mandato do Presidente da República e dos Senadores, de 
maneira individual. Além disso, dispõe sobre a dissolução total da Câmara dos Deputados, depois de um ano da data da posse nos cargos. Assim, pelo projeto, o mandato do Senador pode ser revogado pelo eleitorado do Estado que ele representa e o eleitorado nacional poderá decidir a respeito da dissolução da Câmara dos Deputados, e posteriormente convocar novas eleições a ser realizada no prazo de três meses.

Já no caso do Presidente da República e dos Senadores, a revogação de seu mandato acarretará bem entendido, a sua substituição no respectivo cargo pelo VicePresidente ou pelo suplente de Senador.

Segundo a referida PEC a manifestação seria realizada por iniciativa popular e dirigida ao Superior Tribunal Eleitoral, mediante a assinatura de dois por cento do eleitorado nacional, distribuído pelo menos por sete Estados, com não menos de cinco décimos por cento em cada um deles, ou mediante a assinatura de dois por cento do eleitorado estadual, distribuído pelo menos por sete Municípios, com não menos de cinco décimos por cento em cada um deles.

Merece destaque o fato de que a PEC não exige a condição de cidadão para assinar a petição que é dirigida ao Tribunal Superior Eleitoral, somente se preocupa que o indivíduo mencione qual o município em que está radicado o seu domicílio eleitoral, e isso é um ponto positivo no sentido de dar maior acesso à população para se manifestar e exercitar esse mecanismo de participação direta.

No que tange ao recall do mandato do Presidente da República o projeto seria realizado por intermédio de um requerimento da maioria absoluta dos membros do Congresso Nacional que seria dirigido ao Tribunal Superior Eleitoral.

Portanto, verifica-se ser o Superior Tribunal Eleitoral portador da competência para convocar o referendo revocatório, tanto mediante a provocação popular quanto a do Congresso Nacional.

Além disso, cabe destacar que tal projeto permite que os Estados e os Municípios introduzam o recall em suas constituições estaduais e leis orgânicas, tal como ocorre com os outros instrumentos de participação direta como o plebiscito, o referendo e a iniciativa popular.

\section{Considerações Finais}


No campo político é imperiosa a prevalência do respeito aos princípios constitucionais como a legalidade, a moralidade na esfera político - administrativa.

Nesse sentido, é necessária uma reforma política e, portanto, a lei da ficha limpa, mesmo possuindo um vício que é a violação ao princípio da presunção de inocência, trouxe a disciplina do que seria a análise da vida pregressa do candidato, de forma a dar meios para o Poder Judiciário realmente proceder a uma reforma política.

Portanto, a análise de vida pregressa dos candidatos disciplinada na Lei Complementar n. 135 de 04 de julho de 2010, visa proteger a probidade administrativa, a moralidade para o exercício do mandato, e não deixando a cargo do entendimento dos juízes eleitorais e nem anuindo que tais situações sejam "legisladas" por Resoluções do Tribunal Superior Eleitoral, de forma a afrontar princípios constitucionais.

Além disso, conclui-se que o tipo ideal de democracia é aquela em que há um aprofundamento da identidade popular, possibilitando que as funções públicas sejam exercidas com maior participação dos cidadãos, criando-se novos espaços públicos e novos agentes.

Portanto, a iniciativa popular que originou a lei da ficha limpa é válida devido à participação popular, e deve, portanto, ser respeitada.

Porém cabe a população denunciar atos violadores do bem público realizado por políticos profissionais, ou seja, por aqueles que usam a política como meio de vida, como meros beneficiários daquilo que o cargo pode lhe propiciar.

Para isso, ficou demonstrado no presente estudo a necessidade da inclusão do sistema de revogação de mandatos pelo povo com o fim de dar legitimidade às instituições políticas e democráticas de nosso país.

Seguindo o entendimento de Canotilho (2001, p. 288), ao pressupor a participação igual dos cidadãos, o princípio democrático entrelaça-se com os direitos subjetivos de participação e de associação, que se tornam, assim, fundamentos funcionais da democracia.

Desta forma, ao intensificar a participação direta e ativa do povo, haverá a democratização da democracia através da participação política no Estado Democrático.

Portanto, é imperioso entender que a agenda política de um Estado não é definida apenas pelo governo, mas sim através da mediação estatal entre a comunicação pública e a comunicação do poder, sendo relevante a participação política do cidadão. 
Nesta seara, o projeto de Emenda à Constituição 73/2005 vem corroborar esses preceitos de legitimação popular, de fomento à participação direta da população pela sistemática de revogação do mandato dos agentes políticos que violem o bem público.

Portanto, o projeto de Emenda à Constituição 73/2005 que institui o recall, o referendo revocatório, é coerente com o sistema democrático de participação popular na gestão pública.

Por fim, sabendo que tais questionamentos ainda continuam em aberto no sistema, concluímos o presente estudo com as palavras de Boaventura de Sousa Santos (2007, p. 86), "não haverá justiça mais próxima dos cidadãos, se os cidadãos não se sentirem mais próximos da justiça".

\section{Referências}

BAHIA, Alexandre Gustavo Melo Franco. Ficha limpa e iniciativa popular. A Tribuna Pouso Alegrense, Pouso Alegre, v. 241, p. 6-6, 10 jul. 2010.

BERLINCK, Manoel T. Prefácio. In: WEBER, Marx. Ciência e política: duas vocações. São Paulo: Cultrix, 1967. p. 12.

BONAVIDES, Paulo. Curso de direito constitucional. 10. ed. São Paulo: Malheiros, 2000.

CANOTILHO, José Joaquim Gomes. Direito constitucional e teoria da constituição. Coimbra: Almedina, 2001.

FORST, Rainer. Contextos da justiça. São Paulo: Boitempo, 2010.

MAGALHÃES, José Luiz Quadros de. Direito constitucional, Tomo II. Belo Horizonte: Mandamentos, 2002.

MARTINS, Ives Gandra Martins. Uma breve teoria do poder. São Paulo: Revista dos Tribunais, 2009.

MILL, Stuart. O governo representativo. São Paulo: Escala, 2006.

POLíBIOS. História. Brasília: Universidade de Brasília, 1982.

SANTOS, Boaventura de Sousa. Para uma revolução democrática da justiça. São Paulo: Cortez, 2007.

SGARBI, Adrian. O referendo. Rio de Janeiro: Renovar, 1999.

WEBER, Marx. Ciência e política: duas vocações. São Paulo: Cultrix, 1967. 
ZVIRBLIS, Alberto Antonio. Democracia participativa e opinião pública: cidadania e desobediência civil. São Paulo: RCS, 2006.

Artigo recebido em: 13 de fevereiro de 2011.

Artigo aprovado em:

01 de maio de 2011. 